\title{
Diet and the development of clinical diabetes in man
}

\author{
By Joyce D. BaIrd, Senior Lecturer in Medicine, University of Edinburgh, \\ Honorary Consultant Physician, Western General Hospital, Edinburgh
}

Current concepts in the aetiology of diabetes mellitus in man (Fig. I) emphasize its heterogeneity (Cudworth \& Festenstein, 1978) and the interaction of heredity and environment in the development of all types of clinical diabetes (Keen \& Jarrett, 1976).

There is little evidence to suggest that nutritional factors might play a significant role in the aetiology of idiopathic insulin-dependent (Type I) diabetes. In this type of diabetes the inherited factors are HLA-linked and probably related to the immune response system and the environmental factors are largely unidentified but are thought to include viral infections.

On the other hand, idiopathic insulin-independent (Type II) diabetes shows no association with the HLA system and there is nothing to suggest that viral infections have anything to do with its development. The inherited element is even stronger than in insulin-dependent diabetes (Pyke $\&$ Nelson, 1976) but it is not clear what defect is inherited. That heterogeneity exists within this type of diabetes also is demonstrated by the recent observation that the intense facial flush experienced by some diabetics taking chlorpropamide (CPAF) is a dominantly inherited trait associated with insulin-independent diabetes (Leslie \& Pyke, 1978). The demonstration that this reaction can be blocked with naloxone suggests that these patients may have inherited an unusual sensitivity to enkephalins (Leslie et al. 1979). It has long been recognized that obesity and idiopathic insulinindependent diabetes often co-exist. Although at one time it was considered that obesity was an integral part of the diabetic state, arising from, rather than causing diabetes, most people would now agree that obesity probably acts as a diabetogenic environmental factor in those genetically predisposed to develop diabetes (Baird, 1973a,b).

In this paper I shall consider whether there is any evidence that, obesity apart, specific nutritional factors are involved in the aetiology of Type II diabetes.

\section{Indirect studies}

Probably because it is so difficult to assess accurately the daily intake of food in individual subjects, most studies which have attempted to examine the role of dietary factors in the development of diabetes have been indirect. Such studies are open to the fundamental criticism that the demonstration of an association does not necessarily imply cause and effect.

One of the earliest studies, which illustrates the difficulties and pitfalls very well, was by Himsworth (1949), who noted the fall in the mortality rate from diabetes in the United Kingdom in wartime, demonstrated that this was confined to those $0029-6651 / 81 / 4023-5202 \$ 01.00$ (C) 1981 The Nutrition Society 
PRIMARY (Idiopathic)

TYPE I: INSULIN-DEPENDENT

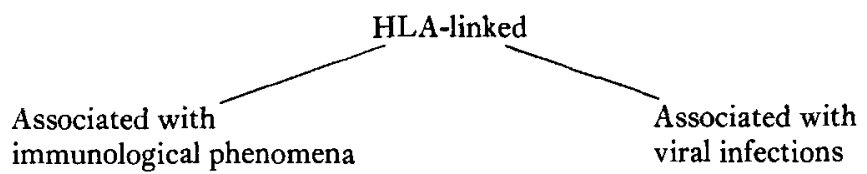

TYPE II: INSULIN-INDEPENDENT

Associated with obesity

Associated with CPAF (enkephalin sensitivity?)

\section{SECONDARY}

TYPE III: SECONDARY TO OTHER DISORDERS

TYPE IV : ASSOCIATED WITH OTHER GENETIC SYNDROMES

Fig. I. Classification of diabetes mellitus.

over the age of 45 years, and suggested a correlation with a reduction in the national consumption of certain foodstuffs.

When we look at the nation's diet between 1900 and 1970 using data derived from the Consumption Level Estimates, published by the Ministry of Agriculture, Food and Fisheries, we find that ( $\mathrm{I}$ ) the amount of food energy available per person varied surprisingly little; between 1900 and $195^{\circ}$ it rose gradually from II $\cdot 28 \mathrm{MJ}$ $(2700 \mathrm{kcal})$ to $12.54 \mathrm{MJ}(3000 \mathrm{kcal})$ daily, and then remained steady; (2) the amount of protein available for consumption, expressed as the percentage energy derived from protein, was also fairly steady at approximately i $1 \%$; $(3)$ the amount of energy provided by fat rose from 32 to $42 \%$; $(4)$ the percentage of energy derived from total carbohydrate eaten dropped from 56 to $46 \%$. Accurate yearly information is not available for World War I, but during ro years of rationing of food during and after World War II, there was an abrupt fall in the percentage of energy derived from fat $(39$ to $32 \%)$ and a simultaneous rise in that from total carbohydrate ( $5 \mathrm{I}$ to $56 \%$ ), corresponding with an abrupt fall in the mortality rate from diabetes.

Himsworth (1949) concluded that high fat diets were diabetogenic. He had previously tried to do other more direct experiments to demonstrate this (Himsworth \& Marshall, 1935). But the consumption of sucrose shows a different trend from that of total carbohydrate and during this period dropped abruptly, exactly like fat. A reduction in the consumption of sucrose could equally well be held responsible for the fall recorded in the death rate from diabetes.

In any case, such studies are unsatisfactory on other counts. For example, there is much evidence that the information on death certificates is usually seriously deficient as far as diabetes is concerned (Cameron, 1966; Tokuhata et al. 1975; Tokuhata, 1976; West, 1978). Moreover, variations in ascertainment of cases of diabetes will occur due to changes in diagnostic criteria and the enthusiasm with which screening is performed. An alternative approach is to study the incidence of diabetes in immigrants coming from under-developed to highly-developed 
countries. One of the first of such studies was reported by Cohen (196r). He showed that diabetes was rare among Jewish immigrants newly arrived in Israel from the Yemen, but, in all age groups over the age of 20 years, the incidence rose steeply after families had lived in Israel for 25 years or more. The prevalence of obesity, ischaemic heart disease, hypertension, hypercholesterolaemia and raised $\beta$ lipoproteins also increased significantly.

When the diets of three groups of Yemenite Jews, i.e. (I) Jews still living in the Yemen, (2) immigrant families of less than ro years standing, and (3) immigrant families who had lived in Israel for over 25 years, were compared (Cohen et al. 196I), there was (a) a slight increase in the daily intake of energy, protein, animal fat, and total carbohydrate in groups 2 and 3 , but none of these differences was statistically significant, (b) a significant increase in the consumption of vegetable oil in settled immigrants and (c) a striking increase in the amount of sucrose consumed by immigrants. Whereas in the Yemen virtually no sugar was eaten and the carbohydrate consumed was almost entirely in the form of starch, about $20 \%$ of the carbohydrate taken by settled immigrants was in the form of sucrose. However, under these circumstances many other things change also. For example, despite the similar energy intake, settled immigrants weighed on average $8.5 \mathrm{~kg}$ more than new immigrants. Presumably energy expenditure must have been less in settled immigrants. Thus, even if dietary factors had any effect, they might have been acting indirectly, for example through an increased incidence of obesity.

In extensive and carefully designed studies in thirteen populations West \& Kalbfleisch (1971) related the prevalence of hyperglycaemia to such variables as race, socio-economic status, diet and obesity. In general they found a positive association between the prevalence of diabetes and the consumption of fat and sugar, and a negative association between diabetes and the total intake of carbohydrate. However, certain inconsistencies in these three associations suggested that they may have been partly coincidental. The most impressive and consistent association in these studies was between the prevalence of diabetes and obesity. Both within and among countries this association was observed consistently to a high degree. Inter-racial differences in prevalence of diabetes were small when racial groups were matched for adiposity.

The same sort of problems arise in relation to dietary fibre. Trowell $(1974 ; 1975)$ has suggested that consumption of dietary fibre and death rates from diabetes are negatively related. However, like sucrose, dietary fibre has associations both positive and negative, with other factors which may protect against or cause diabetes. These include exercise and total dietary carbohydrate (Brunzell et al. 1971) which are thought to protect against diabetes and usually correlate positively with fibre; and dietary fat and sucrose, total energy intake and adiposity which are thought to increase susceptibility to diabetes and are usually negatively correlated with fibre.

There are other problems also relating to the classification and definition of the many different fibres and the variety of metabolic and other effects of different types of fibre, for example on the absorption of different foods (Jenkins, 1979). 


\section{Direct studies}

Few direct studies in man exist. Reference has already been made to Himsworth's (Himsworth \& Marshall, I935) attempt to examine directly the diet of diabetic patients using 'preferment choice' techniques. The reliability of this approach depends on the doubtful assumption that the choice of food under highly artificial conditions by an individual, who moreover knows that he suffers from 'sugar diabetes', is an accurate index of his dietary habits before the diagnosis. Such a technique is particularly limited because of the difficulties of quantitatively assessing dietary habits.

Some years ago now, we attempted to study the relative importance of heredity and environmental factors such as diet and obesity in the development of insulinindependent diabetes more directly by comparing newly diagnosed, untreated diabetic patients aged 45 to 65 with their non-diabetic siblings and with nondiabetic control subjects (Baird I972; 1973a). In all social classes and in both sexes the percentage of obese subjects was found to be significantly higher among those with diabetes compared with non-diabetic subjects. Like other workers who have studied normal healthy subjects (Thomson et al. 1969), we were unable to find any significant difference in either the quality or the quantity of the food eaten by obese and non-obese individuals, when those who had previously received dietary advice were excluded.

However, diabetic patients were found to eat significantly more than nondiabetics of the same sex and social class. The difference was most striking amongst men in the Registrar General's social classes I and II, where the daily energy intake of diabetics was on average $4.2 \mathrm{MJ}$ (1000 kcal) more than nondiabetics. Again, diabetic men in non-manual occupations ate significantly more than non-diabetic men similarly employed and more than either diabetic or nondiabetic subjects engaged in manual work. The diet of diabetics did not appear to differ in any obvious way from that of non-diabetics, except in quantity, and no relationship was found between glucose tolerance and any dietary constituent.

These findings seem to be against the idea that any specific dietary factor is diabetogenic; nor do they fit well with the idea that an excessive energy intake results from the diabetic process. If either of these hypotheses were correct, a relationship between indices of carbohydrate tolerance and dietary factors might be expected. All that we can say is that a high-energy intake and obesity seem to be risk factors for the development of insulin-independent diabetes in man but that the two do not seem to be directly related. They may, however, be linked through differences in energy expenditure resulting from environmental or inherited metabolic variations or both. It seems likely that dietary factors act mainly through their effect on adiposity.

\section{Conclusions}

Non-diabetic individuals have a remarkable capacity to maintain normal glucose homoeostasis despite wide variation in energy intake and dietary components. Any effect of diet on the development of clinical Type II diabetes is likely to be 
apparent only in individuals genetically predisposed to develop diabetes. At present no method exists for identifying these people. Moreover, as already mentioned, diabetes is a heterogenous condition. Dulin \& Gerritsen (1972) have shown that three different species of diabetic animals show a different response to variations in diet. Thus, until we can identify the various genetic groups within insulinindependent diabetes, definitive direct studies, in which various components of the diet are altered under controlled conditions and the metabolic changes monitored, are impossible. Another fundamental problem associated with this type of investigation is that, if the diet is to remain isoenergetic, at least two dietary components have to be altered at any one time.

\section{REFERENCES}

Baird, J. D. (1972). Acta Diabetologica Latina 9, suppl. I, 62 I.

Baird, J. D. (1973a). In Symposium: Anorexia nervosa and obesity, [R. F. Robertson and A. T. Proudfoot, editors]. RCP Edin. Pub. No. 42, p. 83.

Baird, J. D. (1973b). Proc. Nutr. Soc. 32, 199.

Brunzell, J. D., Lerner, R. L., Hazzard, W. R., Porte, D. \& Bierman, E. L. (1971). New Engl. F. Med. $284,521$.

Cameron, D. P. (1966). In Pfizer Medical Monographs I: Diabetes, p. I45 [L. J. P. Duncan, editor]. Edinburgh: Edinburgh University Press.

Cohen, A. M. (196I). Metabolism, 10, 50.

Cohen, A. M., Bavly, S. \& Poznanski, R. (1961). Lancet ii, 1399.

Cudworth, A. G. \& Festenstein, H. (1978). Br. med. Bull. 34, no. 3, 285.

Dulin, W. E. \& Gerritsen, G. D. (1972). Acta Diabetologica Latina 9, suppl. I, 48.

Himsworth, H. P. (I949). Proc. Roy. Soc. Med. 42, 323.

Himsworth, H. P. \& Marshall, E. M. (1935). Clin. Sci. 2, 95.

Jenkins, D. J. A. (1979). Lancet ii, 1287.

Keen, H. \& Jarrett, R. J. (1976). In The Genetics of Diabetes Mellitus, [W. Creutzfeldt, J. Kobberling and J. V. Neel, editors]. p. I I 5. Berlin, Heidelberg, New York: Springer-Verlag.

Leslie, R. D. G. \& Pyke, D. A. (1978). Br. Med. F. 2, 1519.

Leslie, R. D. G., Pyke, D. A. and Stubbs, W. A. (1979). Lancet i, 34I.

Pyke, D. \& Nelson, P. G. (1976). In The Genetics of Diabetes Mellitus, [W. Creutzfeldt, J. Kobberling and J. V. Neel, editors] p. I94. Berlin, Heidelberg, New York: Springer-Verlag.

Thomson, A. M., Billewicz, W. Z. \& Passmore, R. (I969). Lancet i, 1027.

Tokuhata, G. K. (1976). National Commission on Diabetes 3, part I. US Dept. of HEW Publ. (NIH) p. 76.

Tokuhata, G. K., Miller, W. \& Digon, E. (1975). 7. Chron. Dis 28, 23.

Trowell, H. (1974). Lancet ii, 998 .

Trowell, H. (1975). Diabetes 24, 762 .

West, $\overrightarrow{\mathrm{K}}$. M. (1978). In Epidemiology of diabetes and its vascular lesions, p. I59. New York: Elsevier.

West, K. M. \& Kalbfleisch, J. M. (1971). Diabetes 20, 99. 